\title{
RECIST EVALUATION OF THE USE OF SALVAGE RADIOTHERAPY IN LOCALLY ADVANCED BREAST CANCER REFRACTORY TO NEOADJUVANT CHEMOTHERAPY AND UNRESECTABLE
}

Ana Flávia de Paula Guerra Campedelli', Nilceana Maya Aires Freitas', Thais Franco Simionatto', Nathalya Ala Yagi', Carolina Martinelli Bezerril', Jean Teixeira de Paiva', Edesio Martins², Ruffo Freitas-Junior²

${ }^{1}$ Hospital Araújo Jorge, Associação de Combate ao Câncer de Goiás - ACCG - Goiânia (GO), Brazil.

${ }^{2}$ CORA - Centro Avançado de Diagnóstico da Mama, Hospital das Clínicas, Universidade Federal de Goiás - Goiânia (GO), Brazil.

Objectives: Locally advanced breast cancer (LABC) is a major health problem in developing countries. Nearly one third of LABC are resistant to multimodal neoadjuvant treatment. As an alternative to downsize tumor, salvage radiotherapy has been reported as an option. The aim of this study is to verify the use of radiotherapy in the treatment of LABC, to evaluate tumor response by using the Response Evaluation Criteria In Solid Tumors (RECIST) and estimate overall survival. Methods: It is a prospective study including 27 patients LABC that were submitted to salvage radiotherapy between January 2017 and July 2018 at a public hospital; tumor reduction was analyzed by RECIST method. Statistical analysis of tumor response was controlled by immunohistochemistry using Pearson's correlation. The percentage of tumor reduction at the end of radiotherapy was analyzed by Student's T-Test. Overall survival after diagnosis and after Radiotherapy treatment was also analyzed by Kaplan-Meier Curves. All patients were followed by photograph analysis, after signing the informed consent form (TCLE). Results: During a year and a half, 27 patients were included, with a median age of 55 years old. Mean tumor size was $14(3-25) \mathrm{cm}$. The most prevalent immunohistochemistry was luminal tumors (51\%), then triple negative (30\%) and Her2 (19\%). Radiation dose ranged from 40-70Gy; At the end of RT, mean tumor response was $53 \%$ (95\%CI 41-64; $\mathrm{p}<0.001$ ), and after 104 days post RT, mean tumor response was $62 \%$ (95\%CI 49-75; $<<0.001$ ). By RECIST analysis, there was $16 \%$ complete response, $64 \%$ partial response, $16 \%$ stable disease and $4 \%$ progression after RT return. The overall survival (OS) within two years of diagnosis was 56 and $90 \%$ for luminal. After a year of radiotherapy, overall survival was $85 \%$, rather than $50 \%$ in triple negative group ( $p=0,06)$. Conclusion: Radiotherapy should be considered as a form of approach for locoregional control, as an effective treatment to downsize breast cancer tumors with low or absent response to neoadjuvant chemotherapy. 